Kawachi, I. \& Berkman, L. (2000) Social cohesion, social capital, and health. In Social Epidemiology (eds I. Kawachi \& L. Berkman), pp. 174-190. Oxford: Oxford University Press.

McKenzie, K., Patel, V. \& Araya, R. (2004) Learning from low income countries: mental health. British Medical Journal, 329, 1138-1140

Palestinian Environmental NGOs N etwork (2003) The Wall in Palestine. Jerusalem: PEN GON

Summerfield, D. (1999) A critique of seven assumptions behind psychological trauma programmes in war-affected areas. Social Science and Medicine, 48, $1449-1462$.

Summerfield, D. (2002) Effects of war: moral knowledge, revenge, reconciliation and medicalized concepts of 'recovery'. British Medical Journal, 325, 1105-1107.

Thabet, A. \& Vostanis, P. (2000) Post traumatic stress disorder reaction in children of war: a longitudinal study. Child Abuse and Neglect, 24, 291-298.

Van 0 mmeren, M., Saxena, S. \& Saraceno, B. (2005) Mental and social health during and after acute emergencies: emerging consensus? Bulletin of the World Health Organization, 83, 71-76.
For contributions to the

'Associations and collaborations' column, please contact John Henderson, email john.henderson53@ btopenworld.com

Website: http:// www.pscyh.org

\title{
The American Psychiatric Association
}

\section{Michelle B. Riba, ${ }^{1}$ Steven S. Sharfstein ${ }^{2}$ and Allan Tasman ${ }^{3}$}

${ }^{1}$ President 2004-05, Board of Trustees, American Psychiatric Association; Clinical Professor, Associate Chair for Integrated Medical and Psychiatric Services, Department of Psychiatry, University of Michigan, email mriba@umich.edu

${ }^{2}$ President Elect, American Psychiatric Association; President and Chief Executive Officer, Sheppard Pratt Health System; Clinical Professor and Vice Chairman, Department of Psychiatry, University of Maryland ${ }^{3}$ Past President, American Psychiatric Association; Professor and Chair, Department of Psychiatry and Behavioral Science, University of Louisville (KY) School of Medicine

he American Psychiatric Association (APA) is a medical specialty society that represents nearly 36000 psychiatrists from the United States and Canada, as well as around the globe. It is the longest serving medical specialty society. As a leader in the mental health field, the APA continually supports the diagnosis and treatment of patients with mental illnesses, including substance use disorders, and also supports prevention and research. The APA acts as an advocate for psychiatrists and their patients.

The APA works to secure increased funding for psychiatric research and education. It also lo bbies for parity of health insurance coverage for mental illnesses, for patient protection against abuses by managed-care organisations, as well as for the protection of confidential medical records.

The APA, which is accredited by the Accreditation C ouncil for $C$ ontinuing Medical Education, supports the education, training and career develo pment of psychiatrists and other physicians. It offers educational programmes that support lifelong learning through annual scientific meetings, journals and other publications.

The Diagnostic and Statistical M anual of M ental Disorders (D SM), published by the APA, remains the w orld's gold standard for the diagno sis of psychiatric illnesses. The APA's Practice Guidelines show how evidence-based guidelines should be developed. That publication also helps guide clinicians in making scientifically sound decisions in the evaluation and treatment of patients with mental disorders, and it is recognised by the American Medical Association.

The APA also defines and supports professional values, by publishing primers on ethics and working with psychiatrists to provide the highest level of care.

\section{A brief history}

Founded in 1844, the APA formed from a group of 13 superintendents from the then 24 mental hospitals in the U nited States who met in Philadelphia and established the Association of Medical Superintendents of American Institutions for the Insane. The Association's objectives were 'to communicate their experiences to each other, to cooperate in collecting statistical information relating to insanity and assisting each other in improving the treatment of the insane'.

That same year, the first psychiatric journal, the American Journal of Insanity, was published in June by Amariah Brigham, superintendent of the U tica State Hospital in N ew York state.

In 1851, the Association adopted proposals by Thomas Kirkbride, MD, superintendent of the Pennsylvania H o spital for the Insane, for the design and organisation of mental hospitals. These policies dictated the architecture of state hospitals in the $U$ nited States for more than 50 years.

Some 45 years after the Asso ciation's founding, the name was changed to the American MedicoPsychological Association; physicians working in mental hospitals or private offices became eligible for membership in 1892. The Association increased its scope by acquiring the American Journal of Insanity from U tica State H ospital to be its official journal.

In 1917, during the First World War, the Association officially ado pted the Statistical M anual for the Use of H ospitals for M ental Diseases as a system for uniform statistical reporting. $O$ ver the next 3 years, the $N$ ational Committee for Mental Hygiene (publisher of the Manual) successfully introduced the new classification and statistical system into mental hospitals throughout the country. 
Five years later, in 1922, after two earlier changes, the Association adopted its current name - the American Psychiatric Association (APA). The name of the Association's journal became the American Journal of Psychiatry.

As the years moved on, the APA became increasingly involved in helping to ensure proper training of the providers of psychiatric care and the humane, effective treatment of patients. In 1934, the American Board of Psychiatry and N eurology (ABPN) was established under joint sponsorship of the APA, the American $\mathrm{N}$ eurological Association and the American Medical Association to certify standards of training and specialty competence. In addition, the APA expanded its eighth edition of the Statistical M anual to include a new area, 'Standard C lassified N omenclature of D iseases'.

After putting these two areas to gether, the APA published the first edition of The Diagnostic and Statistical Manual of M ental Disorders, now in its 4th edition. In response to physicians' need for psychiatric texts and also to continue the production of the DSM, the American Psychiatric Press, Inc. (APPI) was established in 1981.

To support the needs of its member physicians, the APA formed a Steering Committee on the Practice Guidelines in 1989 to take the lead in describing the best, evidence-based treatments and the range of appropriate treatments available to patients with mental illnesses.

In 2000, the APA reincorporated the membership organisation and its subsidiaries (the American Psychiatric Foundation, the American Psychiatric Institute for Research and Education, the APPI) to position the Association for a greater role in public policy and advocacy. Two years later, in 2003, the Board of Trustees adopted 'A Vision for the Mental Health System', a proactive set of guiding principles for promoting the availability, accessibility and quality of mental health services in the U nited States.

\section{The APA lives out its 'vision'}

Today, the APA has set the following mission and values for the Asso ciation and its membership to follow.

\section{Mission}

The mission of the APA is:

$O$ to promote the highest-quality care for individuals with mental disorders (including mental retardation and substance-related disorders) and their families

o to promote psychiatric education and research

o to advance and represent the profession of psychiatry

o to serve the professional needs of its membership.

\section{Values}

The APA's values concern:

O best standards of clinical practice

O highest ethical standards of professional conduct

o prevention, access, care and sensitivity for patients and compassion for their families o patient-focused treatment decisions

o scientifically established principles of treatment

o advocacy for patients

o leadership

O lifelong professional learning

o collegial support

o respect for diverse views and pluralism within the field and the Association

o respect for other health professionals.

The APA continually strives to meet an everexpanding standard of excellence in medical care, both by its members and for their patients. As an organisation, the following goals have been set forth with the agreement of the APA's Board of Trustees:

$O$ to promote the rights and best interests of patients and those actually or potentially making use of psychiatric services for mental disorders, including mental retardation and substance-related disorders

o to improve access to and the quality of psychiatric services

o to improve research into all aspects of mental illness, including the causes, prevention and treatment of psychiatric disorders

O to improve psychiatric education and training

o to promote optimal conditions for practice and career satisfaction

o to foster collaboration among all who are concerned with the medical, psychological, sociocultural and legal aspects of mental health and illness

o to improve the functioning of the APA in the service of its mission.

\section{The APA today, tomorrow and beyond...}

Since the 2003 release of the 'Vision for the Mental Health System', the APA has been working with its members, allied medical groups and government agencies to ensure that the vision is being implemented. In the past 2 years, it has identified specific objectives and potential strategies to achieve the principles set forth in the 'Vision':

O Advancing insurance non-discrimination. The APA, with support from various groups, has generated widespread support for non-discriminato ry coverage of mental healthcare in the U nited States. The APA continually lobbies for support to end the insurance industry's practice of providing coverage for physical ailments but not comprehensive coverage for mental health needs.

o Protecting patient safety. The APA helped its state asso ciations and district branches to head off legislation that threatens the safety and quality of mental healthcare by allowing non-physicians to prescribe psychotropic medications. The APA continues to monitor this issue and provide support and information to state legislatures where necessary.

- Advancing minority mental healthcare. The APA, with special projects developed by the $O$ ffice of $\mathrm{M}$ inority and $\mathrm{N}$ ational Affairs, is stepping up efforts to
The APA, with support from various groups, has generated widespread support for nondiscriminatory coverage of mental healthcare in the United States. The APA continually lobbies for support to end the insurance industry's practice of providing coverage for physical ailments but not comprehensive coverage for mental health needs. 
improve mental healthcare for minority and underserved communities. The APA is working diligently to attract more minority medical students into the field of psychiatry.

o Raising general awareness of mental health issues and increasing access to care. Through several programmes, the APA is taking an even greater lead in trying to reduce the stigma of mental illness. The $\mathrm{N}$ ational Partnership for W orkplace M ental H ealth, a programme of the American Psychiatric Foundation (APF), is an APA-created coalition of 27 public and private employers that advocate quality psychiatric care for the nation's workforce. In addition, the APA launched a new public information campaign in May 2005 designed to educate the public and reduce the stigma of mental illness and raise public understanding of the field of psychiatry.

In addition to the 'Vision' statement, the APA

The APA's annual
meeting
continues to be
the largest
gathering of
psychiatric
professionals in
the world. This
year, the APA's
158th annual
meeting, in
Atlanta, Georgia,
saw the
presentation of
more than 1000
clinical papers, as
well as symposia,
new research
poster sessions
and workshops.
continues its long-running tradition of promoting excellence in care through lifelong learning and ensuring an adequate supply of well trained psychiatrists. The APA has accelerated development of a range of educational activities for members - from a major recertification initiative, to special sessions for residents at its annual meetings and new online continuing medical education (CME) programmes.

The APA's annual meeting continues to be the largest gathering of psychiatric professionals in the world. This year, the APA's 158th annual meeting, in Atlanta, Georgia, saw the presentation of more than 1000 clinical papers, as well as symposia, new research poster sessions and workshops. Each year, the APA annual meeting provides an opportunity for mental health professionals from all around the world to hear the latest in mental health research and information, as well as a chance for allied groups to gather. In 2004, 8974 international registrants attended the annual meeting in $\mathrm{N}$ ew York. 0 f that total, 1131 were APA members and 7843 non-members. The meeting was the largest in the APA's history, drawing more than 26000 registrants.

In addition to its annual meeting, its subsidiaries - the APPI, the American Psychiatric Institute for Research and Education (APIRE) and the APF - continue to grow and advance as leaders in each of their respective areas.

The APPI has proven itself an able ambassador for psychiatry around the world. By producing the premier collection of psychiatric literature, the APPI promotes quality continuing education and enhances the image of psychiatry as a science-based profession concerned with real medical conditions. It now publishes $75-80 \%$ of the psychiatric literature in English that is most often cited by others. In addition, the APPI's books and journals are available in 30 countries and in 29 languages. D SM - IV $(T R)$ is available in 23 languages alone. In addition, the American Journal of Psychiatry is now the most frequently cited psychiatric journal in the world, as determined by the Institute for Scientific Information.

Through the interlocking efforts of APIRE and the APA Division of Research, the APA works to help expand the science base of psychiatry, strengthen the broad research infrastructure in the field, and improve the quality of care by conducting and supporting clinical and health services research and related educational activity. In 2004, APIRE developed the Parents M ed Guide and Physicians Med Guide for parents and physicians to use when weighing the decision of whether or not to medicate children and adolescents who struggle with major depression. This effort came after a decision by the US Food and D rug Administration to include 'black box' warnings for children and adolescents on antidepressant medication. As this issue became the subject of public debate, the APA and APIRE took multiple actions to provide the public with the most accurate information about the drugs, endeavouring to ensure proper prescription and usage of these psychotropic medications for young patients.

The APF, the APA's self-supported charitable arm, has become involved in funding both research and educational initiatives that propel the profession of psychiatry forwards. The APF provides grants for programmes in public education that promote the early recognition of mental illnesses, remove financial, cultural and societal barriers to quality mental healthcare, and encourage those with mental illnesses and their carers to participate actively in their treatment. The APF also administers fellowships that educate psychiatry residents about development of public policy related to the care of patients and aw ards that recognise excellence in psychiatric research.

W ith so many initiatives, the APA is an ever-evolving body. But through this advancement, its mission, values and goals drive its actions and lead psychiatry into the future. With the leadership of the board, the strong foundation of its highly skilled members, and the perseverance of its professional staff, the APA will continue to be the leading mental health association in the U nited States and across the globe. 